\title{
Randomised trial of continuous nasogastic, bolus nasogastric, and transpyloric feeding in infants of birth weight under $1400 \mathrm{~g}$
}

\author{
P D Macdonald, C H Skeoch, H Carse, F Dryburgh, L G Alroomi, P Galea, G Gettinby
}

\begin{abstract}
Forty three infants under $1400 \mathrm{~g}$ were fed by a bolus nasogastric, continuous nasogastric, or transpyloric route. There were more complications with transpyloric feeding and no identifiable benefits in the growth rate, oral energy input, or chosen biochemical indices of nutrition. Bolus or continuous nasogastric feeds rather than transpyloric are better routine methods in infants of low birth weight.
\end{abstract}

Feeding tiny preterm infants is vitally important and yet may be very difficult. Transpyloric feeding has been used widely in the past. However, different comparisons with nasogastric feeding have produced conflicting results. ${ }^{1-3}$ This study compares the growth of babies randomised to receive one of three methods of feeding: hourly bolus nasogastric feeding (bNG), continuous nasogastric feeding (cNG) and continuous transpyloric feeding (TP).

\section{Patients and methods}

A one year prospective study (January to December 1987) enrolled 43 infants of birth weight under $1400 \mathrm{~g}$. The babies initially received total parenteral nutrition. On day 2 the feeding route was determined for each baby by opening a sealed envelope, and milk feeding started with $1 \mathrm{ml} /$ hour of SMA low birthweight formula (Wyeth). Milk feeds were increased by increments of 0.5 to $1.0 \mathrm{ml} /$ hour and supplemented with parenteral nutrition until such time as the infants were tolerating full energy and fluid requirements given as the low birthweight formula at $150 \mathrm{ml} / \mathrm{kg}$ a day.

The position of the nasogastric tubes was confirmed by aspiration and $\mathrm{pH}$ testing. Transpyloric tubes were sited in the second and third part of the duodenum and the position was confirmed radiologically. The infants were fed by the selected method until they reached a weight of $1600 \mathrm{~g}$ after which they all received bolus nasogastric feeding. No baby received energy supplements during the trial period. Infants who received expressed breast milk were excluded from the trial as were those with major congenital malformations, those who developed hydrocephalus, and those with intrauterine viral infections. Weekly anthropometric measurements of length (using the Pedobaby babymeter), weight, and occipitofrontal circumference were made. In addition triceps and quadriceps skinfold thicknesses were measured.

Weekly blood samples were obtained and analysed using standard biochemical methods for alkaline phosphatase (German Optimised method: EC3.1.3.1.), urea (urease method), albumin (bromocresol purple method) ${ }^{4}$ prealbumin, and transferrin (both were assayed by immunodiffusion and immunoturbidimetric methods). Prealbumin, ${ }^{5}$ transferrin, ${ }^{6}$ and albumin $^{7}$ were chosen as useful indices of protein nutrition with their differing half lives of two days, eight days, and 20 days respectively.

Fifteen babies started in the TP group, but only 10 completed the study as three died before milk feeding was established, one was transferred to another hospital aged 2 weeks, and in one it proved impossible to site a feeding tube distal to the pylorus despite five attempts. Thirteen babies enrolled in the cNG group, one of whom was transferred to another hospital aged 2 weeks, while 12 completed the study. Fifteen babies enrolled in the bNG group, three of whom died before milk feeding was established, leaving 12 to complete the study. All deaths were within the first week, five being due to massive intraventricular haemorrhage in babies between 24 and 28 weeks of gestation. The other death was due to severe respiratory distress syndrome with unresponsive respiratory failure in an infant of $\mathbf{3 0}$ weeks' gestation.

Mean birth weight (g) and range of the survivors in each group was: TP $1177 \mathrm{~g}$ (840 1400), bNG $1203 \mathrm{~g}$ (740-1400), cNG $1137 \mathrm{~g}$ (860-1390). Mean gestation in weeks and range was: TP 28.9 (26-32), bNG 29.1 (25-34), cNG $28 \cdot 5$ (26-32). In each nasogastric group nine out of 12 were ventilated and in the transpyloric group seven out of 10 were ventilated.

\section{Results}

Each infant's daily energy input per kilogram, achieved in the form of milk, was calculated for the first four weeks or until exit from the study at $1600 \mathrm{~g}$ or whichever occurred first. There was no significant difference in milk input between any of the groups during this period (one way analysis of variance on $\log$ transformed data) (table 1). Comparison of the mean daily energy

Table 1 Daily oral energy input (mean (SD) values measured in $\mathrm{kJ} / \mathrm{kg} /$ day)

\begin{tabular}{llll}
\hline \multicolumn{4}{l}{ Feeding group } \\
\cline { 2 - 4 } & TP & $c N G$ & $b N G$ \\
\hline Week 1 & $160(109)$ & $164(97)$ & $134(101)$ \\
Week 2 & $365(168)$ & $349(181)$ & $386(151)$ \\
Week 3 & $370(189)$ & $378(189)$ & $420(185)$ \\
Week 4 & $399(176)$ & $378(197)$ & $403(155)$ \\
\hline
\end{tabular}

TP, transpyloric; cNG, continuous nasogastric; bNG, bolus nasogastric feeding. 
input of the three groups once they were no longer receiving any supplementation with parenteral nutrition also shows no significant difference (one way analysis of variance): TP $496 \mathrm{~kJ} / \mathrm{kg} /$ day, cNG $512 \mathrm{~kJ} / \mathrm{kg} /$ day, bNG 487 $\mathrm{kJ} / \mathrm{kg} /$ day with pooled SD $46 \cdot 6$.

There was no significant difference between the groups (one way analysis of variance) in the length of time required to achieve full enteral feeding (bNG mean 18.6 days, cNG mean 20.7 days, TP mean $15 \cdot 8$ days with pooled SD $17 \cdot 8)$. However, there were two babies in each nasogastric group who took more than $\mathbf{5 0}$ days to tolerate full enteral feeding while the maximum time required in the TP group was 37 days.

Each infant's weight, length, and occipitofrontal circumference were plotted against gestational age; mean (SD) was calculated for each group weekly up to 36 weeks of gestation. On the basis of these comparisons we found no difference in the growth patterns of the three groups (figure). The weekly increase in these parameters was used to calculate velocity measurements, which showed no significant difference (one way analysis of variance) between the three groups (table 2).

We did not find the skinfold thicknesses a

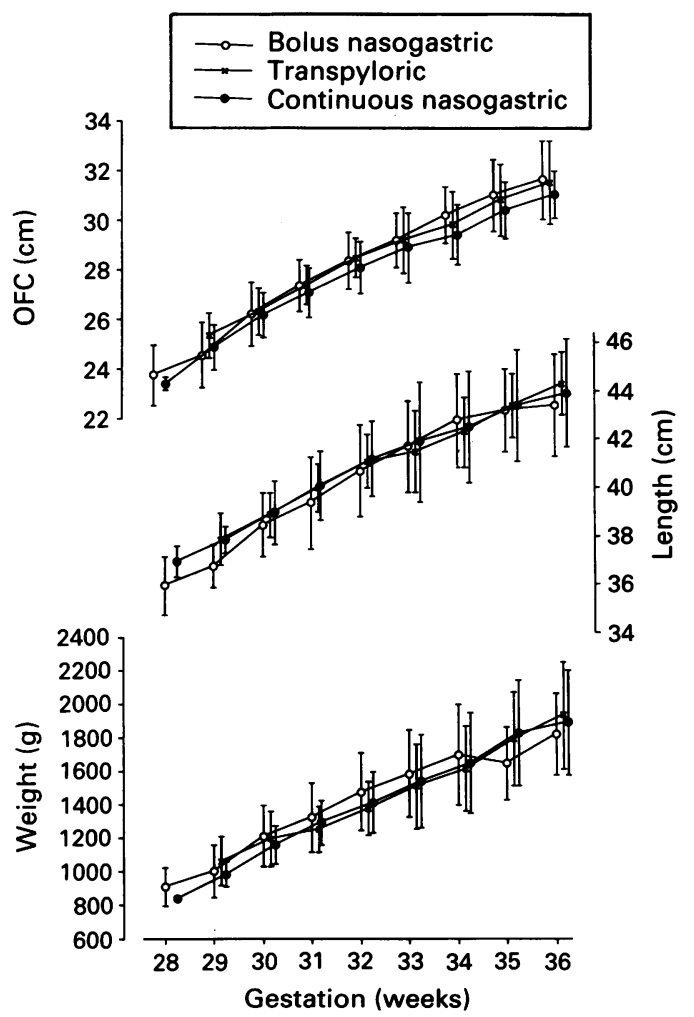

Mean (SD) weight, length, and occipitofrontal circumference $(O F C)$ related to gestational age.

Table 2 Growth velocities mean (SD) values

\begin{tabular}{llll}
\hline & \multicolumn{2}{l}{ Feeding group } & \\
\cline { 2 - 4 } & $T P$ & $c N G$ & $b N G$ \\
\hline Weight gain (g/week) & $157 \cdot 6(59 \cdot 6)$ & $155 \cdot 3(47 \cdot 6)$ & $167 \cdot 8(49 \cdot 6)$ \\
OFC gain (mm/week) & $10 \cdot 62(2 \cdot 92)$ & $9 \cdot 40(2 \cdot 32)$ & $9 \cdot 92(2 \cdot 07)$ \\
Length gain (mm/week) & $11 \cdot 30(4 \cdot 06)$ & $10 \cdot 41(4 \cdot 40)$ & $11 \cdot 45(4 \cdot 56)$
\end{tabular}

TP, transpyloric; cNG, continuous nasogastric; bNG, bolus nasogastric feeding; OFC, occipitofrontal circumference. reliable method of assessing growth in these infants of low birth weight as there was marked interobserver variability between the two people responsible for the measurements. We have found a striking similarity in growth rate for all babies irrespective of their individual starting point or method of feeding.

The initial biochemical data on entry to the study and on exit at $1600 \mathrm{~g}$ are compared in table 3. There was a slight rise in albumin and fall in urea over the period of the study. Similarly, there was a small increase in alkaline phosphatase and fall in transferrin in all groups. When changes between the final and initial value of each subject were analysed (one way analysis of variance), there was no evidence of significant differences between the biochemical results for the three groups. Prealbumin concentrations were not used in assessing the efficacy of the feeding methods because of methodological difficulties. The immunoturbidimetric assay correlated with an immunodiffusion method when initially compared using adult plasma samples. However, there was no correlation when the methods were retrospectively compared using samples from other babies of very low birth weight. Thus the assay results were considered unreliable and not used.

The complications occurring in each group are shown in table 4 . The TP group required a total of 31 radiographs in the 10 survivors performed solely for tube positioning. All proved episodes of aspiration occurred when the babies were over $1600 \mathrm{~g}$ and were being fed larger volumes less frequently by a bolus nasogastric route. There were two radiographically proved cases of necrotising enterocolitis one each in TP and $\mathrm{cNG}$ groups. In the same groups there were two further cases suspected on clinical grounds but not radiologically confirmed and both resolved quickly on antibiotic treatment and short term withdrawal of milk. Four of the 10 babies in the group receiving transpyloric feeding required treatment for gastric bleeding. No infant had gastric bleeding while receiving nasogastric feeding although one infant fed by this method developed bleeding before starting on milk. The high rate of gastric bleeding in the TP group was significant $(p<0.05$ Fisher's exact test).

Table 3 Plasma biochemical concentrations (mean (SD) values)

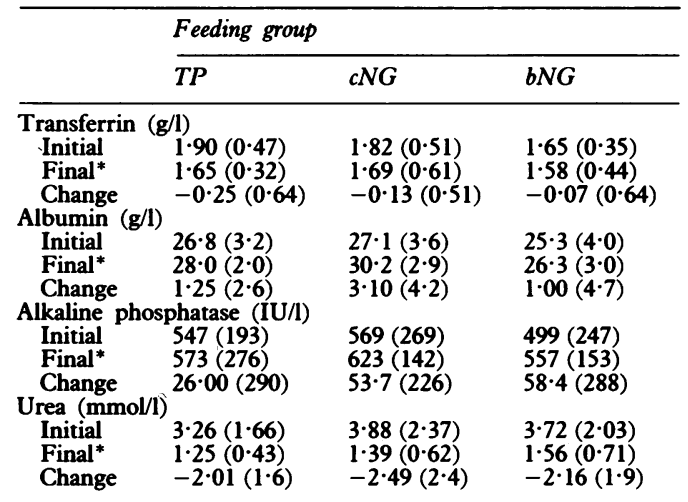

TP, transpyloric; cNG, continuous nasogastric; bNG, bolus

"Final figures at exit from study, ie when weight reached $1600 \mathrm{~g}$. 
Table 4 Complications in 34 survivors

\begin{tabular}{|c|c|c|c|}
\hline \multirow[t]{2}{*}{ Complications } & \multicolumn{3}{|c|}{ Feeding group } \\
\hline & $\begin{array}{l}T P \\
(n=10)\end{array}$ & $\begin{array}{l}c N G \\
(n=12)\end{array}$ & $\begin{array}{l}b N G \\
(n=12)\end{array}$ \\
\hline Extra abdominal radiographs & $31(1-9)$ & 0 & $\mathbf{0}$ \\
\hline $\begin{array}{l}\text { Proved aspiration } \\
\text { Necrotising enterocolitis }\end{array}$ & $2^{*}$ & $1^{*}$ & 0 \\
\hline Proved & 1 & 1 & $\mathbf{0}$ \\
\hline Probable & i & i & $\mathbf{0}$ \\
\hline Septicaemia (Staphylococcus epidermidis) & 1 & $i$ & 1 \\
\hline Gastric bleeding & 4 & 0 & it \\
\hline
\end{tabular}

TP, transpyloric; cNG, continuous nasogastric; bNG, bolus nasogastric feeding *After reaching $1600 \mathrm{~g}$ †Before milk started. biochemical measurements or the anthropometric data. Transpyloric feeding requires more radiological exposure and more early handling. It is also associated with a significant incidence of gastric bleeding, although we have not seen this reported before. It seems likely that bypassing the stomach fails to neutralise the gastric acid secreted as a result of gastrin stimulation provoked by the presence of milk in the small bowel.

Our results suggest that the transpyloric route does not have a routine role in feeding preterm infants. There are significant disadvantages and no nutritional benefits. Nasogastric feeding either continuously or by frequent boluses can achieve similar oral energy input and appears both safe and effective. Previous reports of aspiration with nasogastric feeding may be related to inappropriately high volumes being given without monitoring of gastric aspirates. More widespread use of parenteral nutrition now allows a more controlled introduction of nasogastric feeding. We would recommend reserving transpyloric feeding for those infants who persistently fail to tolerate nasogastric feeding. in infants under $1300 \mathrm{~g} .{ }^{1}$ They found better growth in the nasoduodenal group related to a higher energy input. Studies by Pereira and Lemons and by Laing et al, including larger babies up to $1700 \mathrm{~g}$ and $1500 \mathrm{~g}$ respectively, found no difference in growth between infants receiving bolus nasogastric feeding and infants receiving nasoduodenal feeding. ${ }^{2} 3$ Pereira and Lemons found no difference in total protein levels in their two groups; and our wider range of biochemical data also shows no advantage from transpyloric feeding. The earlier studies ${ }^{12}$ included few ventilated infants (none and under $50 \%$ respectively) while $74 \%$ of our 34 survivors were ventilated.

Our results show no nutritional benefit from transpyloric feeding either on the basis of the
1 Van Caillie M, Powell GK. Nasoduodenal versus nasogastric feeding in the very low birth weight infant. Pediatrics 1975;56:1065-71.

2 Pereira GR, Lemons JA. Controlled study of transpyloric and intermittent gavage feeding in the small preterm infant. Pediatrics 1981;67:68-71.

3 Laing IA, Lang MA, Callaghan O, Hume E. Nasogastric compared with nasoduodenal feeding in low birth weight infants. Arch Dis Child 1986;61:138-41.

4 Hill PG, Wells TNC. Bromocresol purple and the measurement of serum albumin. Ann Clin Biochem 1983;20:264-70.

5 Socolow EL, Woeber KA, Purdy RH. Preparation of ${ }^{131}$ I labelled human serum prealbumin and its metabolism in normal and sick patients. $\mathcal{F}$ Clin Invest 1965;44:1600-9.

6 Ingenbleek Y, Van den Schreick H, De Nayer P, et al. Albumin, transferring and thyroxine binding prealbumin/ retinol binding protein complex in assessment of malnutrition. Clin Chim Acta 1975;63:61-7. N Engl F Med 1972;286:748-54.
7 Rothschild MA, Oratz M, Schrieber SS. Albumin synthesis. 